\title{
Physically-based modelling for sheet metal cone parts forming under blast loading
}

\author{
Roozbeh Alipour* \\ Department of Mechanical Engineering, Mahshahr Branch, Islamic Azad University, Mahshahr, Iran
}

Received: 3 September 2020 / Accepted: 6 January 2021

\begin{abstract}
Forming sheet metals under blast loading or the explosive forming technique has many advantages for productions, but it is restricted due to its accuracy. This paper introduces a novel theoretical-empirical study for explosive sheet metal forming based on the simple plasticity principles. It provides a method of producing the sheet metal cone parts forming under blast loading, including an analytical model and experimental validation. Firstly, a theoretical-empirical model for cone forming based on underwater explosion employing the impulse method is developed. The model on the whole revealed the relationships among the geometrical parameters of forming a process that is very useful to predict the certain explosive mass for complete forming a cone part. Afterward, a series of experiments are conducted to validate the developed model and also for the required modification in the solution. Comparing the theoretical-empirical solution and experimental results, the ability of the presented model for estimation of the explosive mass is demonstrated. Experimental results show that the theoretical model matched the experiments well.
\end{abstract}

Keywords: Blast loading / explosive forming / high rate forming / impulse method / standoff distance / underwater explosion

\section{Introduction}

Cone forming is one of the sophisticated and difficult areas in sheet metal forming processes [1]. In the conventional deep drawing method, failure is too likely to come to pass on the specimen because of the low-contact area of the sheet with the punch in the first steps of forming. Besides, since most of the sheet surface in the area between the punch tips and the blank holder is given free rein to form, wrinkles may occur on the flange or product wall $[2,3]$. Therefore, conical parts are normally made by spinning [4,5], explosive forming [6-13], hydroforming [14-16], electrohydraulic forming [17] or multi-stage deep drawing processes $[14,18-20]$. In the meantime, the application of explosive forming rises from reducing manufacturing lead times and cost and increase material utilization and reduce waste [21]. The main elements associated with explosive forming of sheet metals are: explosive material or charge, die, the energy transfer medium and the safe physical site. The explosive could be in contact with the material or positioned at a distance from the material which is the

\footnotetext{
* e-mail: r.alipour@mhriau.ac.ir
}

so-called stand-off. The process can be conducted in air, water, plasticine and Jelly, or other transfer media [22-30].

Explosive forming has achieved considerable success and popularity during recent decades. In fact, the need to investigate possible forming processes for manufacturing all parts of the simplified component has resulted in explosive forming being developed [31]. Increased the mentioned development has led to several researches on the explosive forming of sheet metals from analytical, numerical and experimental points of view [32]. Zhang et al. [33] reported a numerical analysis on the deformation feature of the explosive die-forming process. In their research, the shock pressure which was generated from an explosive was considered as the punch in the conventional deep drawing process. It is realized that the movement of the periphery blank and the thickness variation of product are more sensitive to the frictional coefficient than the radius of the die. An experimental and numerical analysis of explosive free forming was carried out by Akbari Mousavi et al. [34] to eliminate most of the trial-and-error work, and provide relatively close approximation of process parameters. Results show that the friction coefficient and blank holder force must be sufficient and optimized in order to prevent uneven drawing and wrinkling. Similarly, the elongation of aluminum alloy sheet metal in the free explosive forming 
process using the finite element method has been investigated $[22,24,35]$. Results were compared with the experimental tests and in the case of elongation limit, the superiority of explosive forming to similar methods like hydroforming and deep drawing was proven. Wijayathunga and Webb [36] developed a FE model to simulate the experimental tests for the explosive forming of a brass square cup with the presence of a lead plug. The plug was a soft material which was inserted in contact with the plate, in between the source of the explosion and the plate. Thus, the pressure wave instead of reaching the plate directly exerts itself on the plate via the plug. Results showed that the plug acts as a conduit to transfer the energy at a relatively slower rate to the plate. Although most investigations to date have focused on the die-explosive forming however, some established works have been published in studying the none-die explosive forming in order to fabricate the spherical vessels [37-42].

There are some studies contributed to the cone explosive forming. However, most researches carried out so far, are military applications-oriented and thus may have not been published [34]. Tardif [43] was the first person who offered an underwater explosion (UNDEX) to produce cones by circular blanks. Except for trailblazer and novelty, his work was not clasped a comprehensive experimental or analytical investigation. The only relative comprehensive experimental investigation about explosive forming of cones is Johnson and Travis's [44] research. Emami and Alavi Nia [6] developed a numerical solution to simulate the explosive metal forming of a circular steel blank into a cone. Arbitrary Lagrangian-Eulerian (ALE) method was employed for simulation. This work was limited to certain materials and geometry. The authors could not find a direct discussion focused on the theoretical investigation of explosive forming of cones except for Alipour et al. [45] research.

Although manufacturers have been using explosive energy for a long time however, explosives can be effective when the detonation energy is controlled [46-49]. Charge type and mass play an important role to control the detonation energy and impulse. Therefore, a part of studies in the area of explosive forming has been concentrated on calculating or optimizing the charge mass. Numerous theoretical methods have been developed that can be applied to analyze the explosive forming process and estimation of charge mass [50-52]. Of these are the geometric method, energy method and impulse method. These methods attempt to anticipate the amount of energy transmitted to the specimen [34]. The development of computers and various numerical models allows researchers to model this complicated process. Gulcan et al. [53] used the genetic algorithm to optimize the explosive mass in explosive forming techniques. In this research the explosive forming was assumed as a type of deep drawing process and by using deep drawing formulas and explosion pressure formulas, it was shown that, process parameters can be chosen by genetic algorithm to make the explosive mass minimum. Application of generalized polynomial neural networks to optimize the process parameter such as charge mass has been reported by Nariman-zade et al. [54]. Balasubramaniam et. al predicted the explosive mass required for forming of low carbon steel sheet into a stepped disc shape from a theoretical consideration [55]. Fengman et al. [51] computed the strain energy of plastic deformation of the workpiece in order to arrive at a rational method for predicting the amount of explosive charge needed for a particular forming operation. The effect of strain rate was neglected in Fengman et al. study. Alipour et al. [52] established an equation to estimate the charge mass for explosive forming of cones through the energy method. However, the effect of work hardening, redundant work, strain rate, friction and wall thickness variation in the product were ignored.

This shows the significance of the present study which aims to investigate the detonation energy and explosive mass required for cone forming with respect to the geometrical specification of forming process, material type, strain rate, work hardening, redundant work and friction between the workpiece and die. Towards this end, a theoretical-empirical model based on the impulse method is derived to estimate the explosive mass required for perfect forming. The model is validated against a series of experimental results. The error of the primary analytical model is determined and tried to modify the model by employing and manipulating the forming process parameter. Finally, the model robustness is checked through a series of additional experiments.

\section{Cone explosive forming: concept and terminologies}

This section provides general information on the explosive forming process and terminologies used in the experimental setup. An open die system was adopted in this study to form the cone shape as shown in Figure 1.

The blank is positioned over the die without the need of any blank holder. Air is then evacuated from the die through a non-return valve located at the vacuum line beside the die body. After that, the whole forming die is transferred and located at the center of the explosion container and surrounded with water. The explosive mass is held on the top of the die at a prescribed distance (standoff) using a fixture. When the explosion occurs, a pressure pulse of very high intensity is produced. Instantaneously, a gas bubble is developed and expands spherically and then collapses. Subsequently, the pressure pulse impinges against the blank and it is pushed into the conical die and becomes a cone. More detail of the test procedure can be reach out in $[56,57]$.

\section{Analytical model frameworks}

The analytical study was conducted based on the impulse method. The steps used to establish an analytical equation were summarized as follows:

First (A), determine the impulse received by a circular sheet metal subjected to UNDEX $\left(I_{n}\right)$ at a given standoff via impulse method which is based on the empirical survey of underwater explosion [58] (Sect. 5.1). Constants describing the power of explosion based on the explosive 


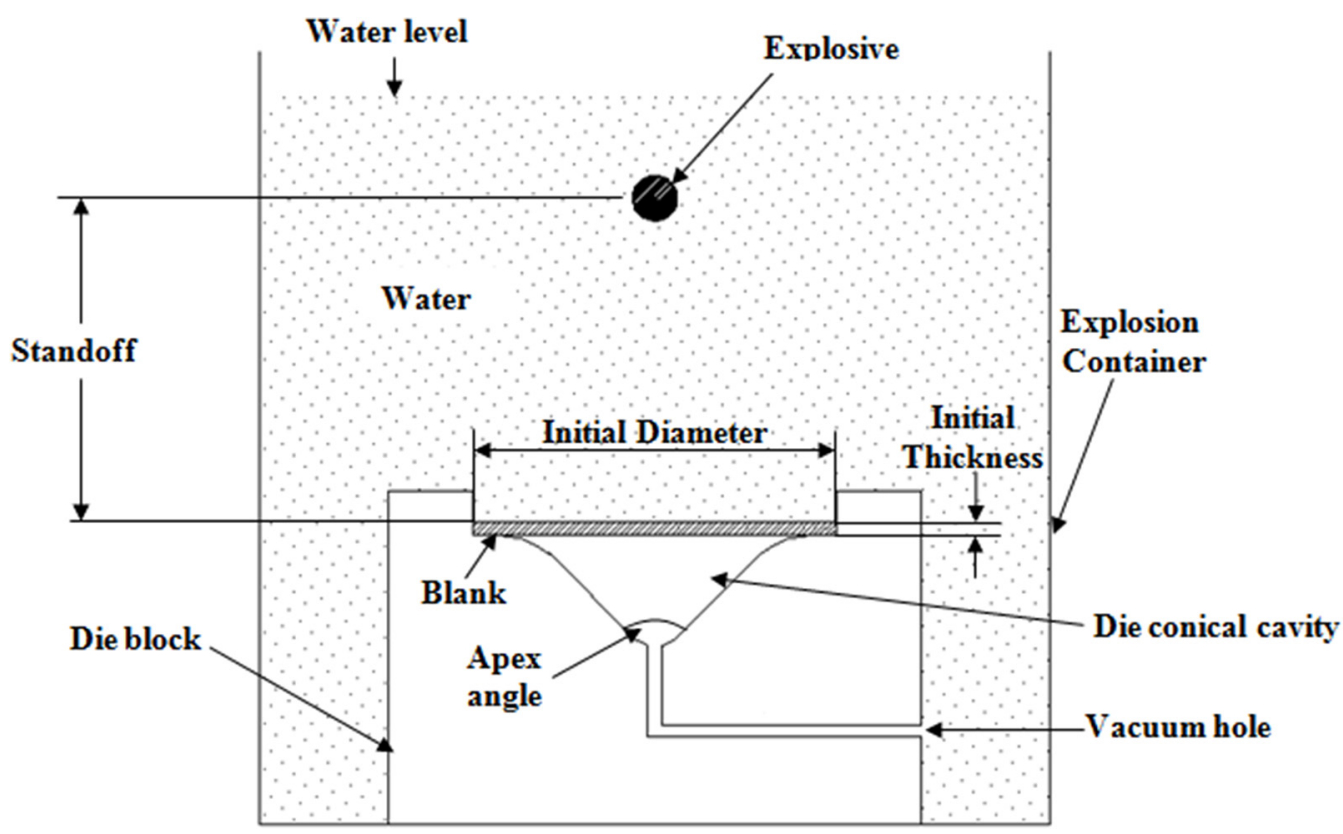

Fig. 1. Schematic diagram of an open die system used in cone explosive forming.

material type in the impulse formula were obtained from the literature [59-61]. Second (B), calculate the strain energy $(U)$ required for forming the blank sheet into a cone by considering the effects of friction, redundant work and strain rate based on the definition of plastic work [62] (Sect. 5.2). The velocity and consequently the impulse required for cone forming $\left(I_{s h}\right)$ are calculated. Constants and coefficients of friction [62], redundant work [62] and strain rate [63] were taken from literature (Sects. 5.1.3 and 5.1.4). Lastly (C), equate the impulse required for cone forming with the impulse received by the circular sheet metal for estimating the explosive mass $(W)$ required to form a cone (Sect. 5.5). Figure 2 shows a summary of theoretical study steps.

\section{Experimental procedure}

Specification of materials, setup configurations and experimental procedures are presented in this section. The required explosive charge mass to obtain the completed forming is experimentally studied.

\subsection{Material specifications}

Commercial types of copper, steel and aluminum sheets were selected in this research. The sheet specimens were firstly cut into a disk shape by the wire-cut machine to obtain better geometric precision. The mechanical properties of the specimens were determined based on ASTM E8M standards. Engineering stress-strain curves of specimens extracted from the test are shown in Figure 3. The specifications of specimens are listed in the Table 1.

The explosive used in the experimental investigations is C- 4 or Composition C- 4 which is a common variety of the

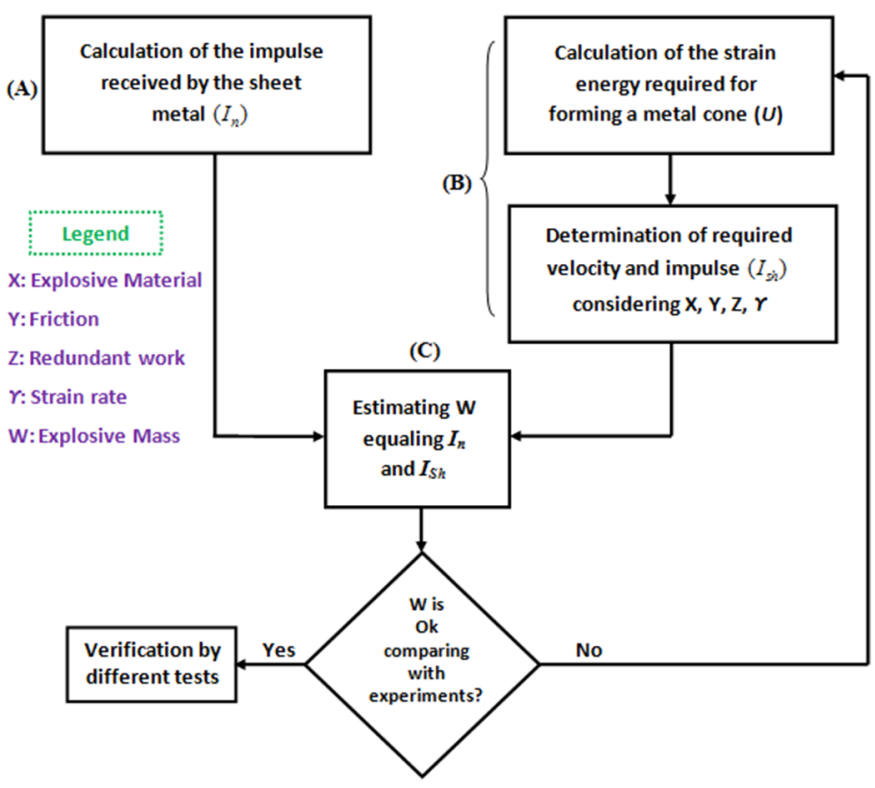

Fig. 2. Steps followed in the theoretical study.

plastic explosive family known as Composition C. This material is composed of explosives, a plastic binder and plasticizer to make it malleable, and usually a marker or odorizing taggant chemical. C-4 has a texture similar to modeling clay and can be molded into any desired shape with good water resistance.

\subsection{Field experiment trials}

Blanks were positioned on the die and sealed by the modeling clay to prevent the water leakage before the 
Table 1. Specifications of blank materials.

\begin{tabular}{lllll}
\hline Material & Type & $\begin{array}{l}\text { Elastic modulus } \\
(\mathrm{GPa})\end{array}$ & $\begin{array}{l}\text { Initial yield stress } \\
(\mathrm{MPa})\end{array}$ & $\begin{array}{l}\text { Ultimate yield } \\
\text { Stress }(M P a)\end{array}$ \\
\hline Steel & AISI 1006 & 209 & 246 & 335 \\
Copper & Cu-ETP & 120 & 177 & 225 \\
Aluminum & $6061-\mathrm{O}$ & 62 & 63 & 85 \\
\hline
\end{tabular}

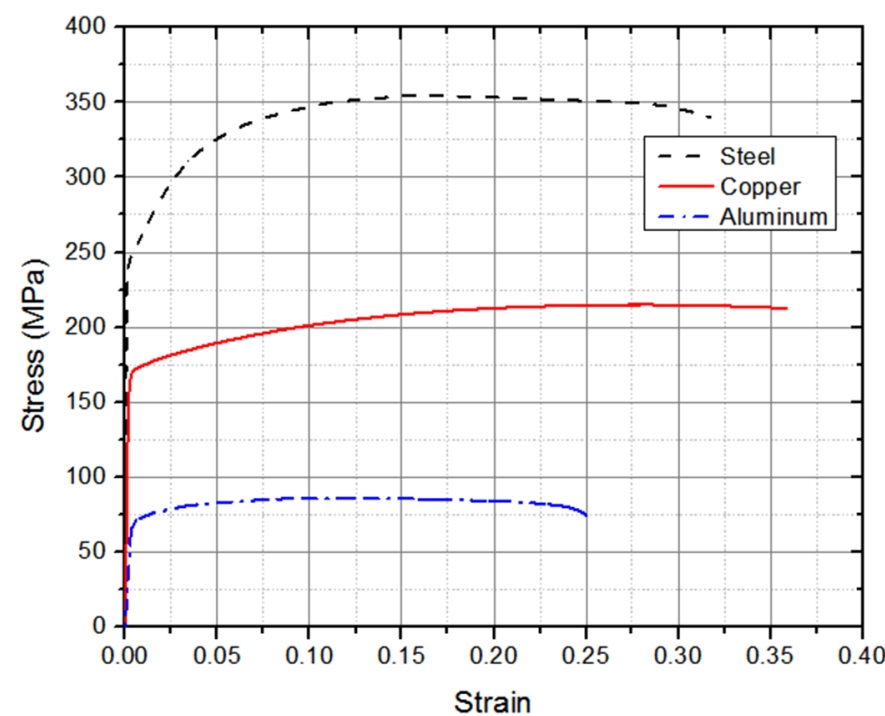

Fig. 3. Engineering stress-strain curves of blank materials.

explosion. Design, analysis and manufacturing of cylindrical dies used in this study have been carried out based on the loading process which is applied in this type of operation $[8,64]$. The explosive charge was placed centrally at the stand-off distance. The detonator and firing wire were attached and covered by the black tape, then the whole assembly is lowered into the tank which is located inside a hole dug-out in the ground. The tank should endure frequent impacts due to the explosion shock sans rupturing [64]. After obtaining the desired vacuum and the circuit checked with an ohmmeter, the exploder is connected and the charge detonated. The depth of submergence for all specimens was equal to $1000 \mathrm{~mm}$. All the experiments were implemented in a constant volume of water. Some facilities of the experiments are shown in Figure 4.

\subsection{Experiments}

Table 2 illustrates the experimental plan. In the second column of this table, a simple code including five-parts (e.g., $\mathrm{Cu}-\mathrm{L}-\mathrm{S}-\mathrm{W}-1$ ) was created for each specimen to differentiate between trials. The first part of code is an indicator for the blank material $(\mathrm{Cu}, \mathrm{St}$ and $\mathrm{Al})$. The initial thickness (L: $0.8 \mathrm{~mm}, \mathrm{M}: 1 \mathrm{~mm}, \mathrm{H}: 1.2 \mathrm{~mm}$ ), initial diameter of the blank (S: $100 \mathrm{~mm}, \mathrm{~B}: 110 \mathrm{~mm}$ ), half apex angle of the die (O: $\left.45^{\circ}, \mathrm{W}: 60^{\circ}\right)$ and standoff distance (1: 130, 2: 150, 3:170) are the other part of five-parts codes, sequentially. Where in Table $2, t_{0}, D_{0}, \theta$ and $S_{d}$ are the initial thickness of the blank, initial diameter of the blank, half apex angle of the die and standoff distance, respectively.

During the trials, the initial explosive mass was taken from the analytical equation as a starting point. It was varied gradually until it reached a value that was sufficient to complete the cone profile, that is, height of the cone equals to the depth of the die without rupture. At this condition, the trial was repeated two times for confirming the results of explosive mass.

\section{Establishing the physical model}

The main objective of this is to establish an equation based on the impulse method that can get an estimation of explosive mass required for forming a metal cone. This section describes establishing the theoretical equation via a physical modeling for estimating of explosive mass required for cone forming based on the methodology described in Figure 2.

\subsection{Determination of UNDEX impulse}

A lower bound experimentally estimation available for the UNDEX of the small chemical amount of explosive that is useful for investigation of the plastic deformation of structures is the impulse method [65]. The impulse method is based on the empirical survey of UNDEX [58] and thus it is just creditable for the water as the transfer medium [34]. The integrated impulse per unit area, $I_{t}$, (in psi) in a shockwave (free impulse and without incident to anything) is expressed as [60].

$$
I_{t}=\frac{\beta W^{\frac{\varphi+1}{3}}}{S_{d}^{\varphi}}
$$

where $W$ is the explosive mass in pounds and $S_{d}$ is the standoff in the range in inch. $\beta$ and $\varphi$ are the explosive constants that the value of them for $\mathrm{C} 4$ has been reported 19.8 and 0.98 , respectively [59-61]. Therefore, for a given explosive mass the impulse of shockwave would be expected to vary as $\beta\left(1 / S_{d}\right)^{\varphi}$.

Ezra (1973) showed the after an UNDEX, impulse extends radial towards out of shockwave. Also, he indicated that when an incident between shockwave and a sheet happens, just the normal component of impulse $\left(I_{n}\right)$ is effective to create the perpendicular velocity in the sheet 

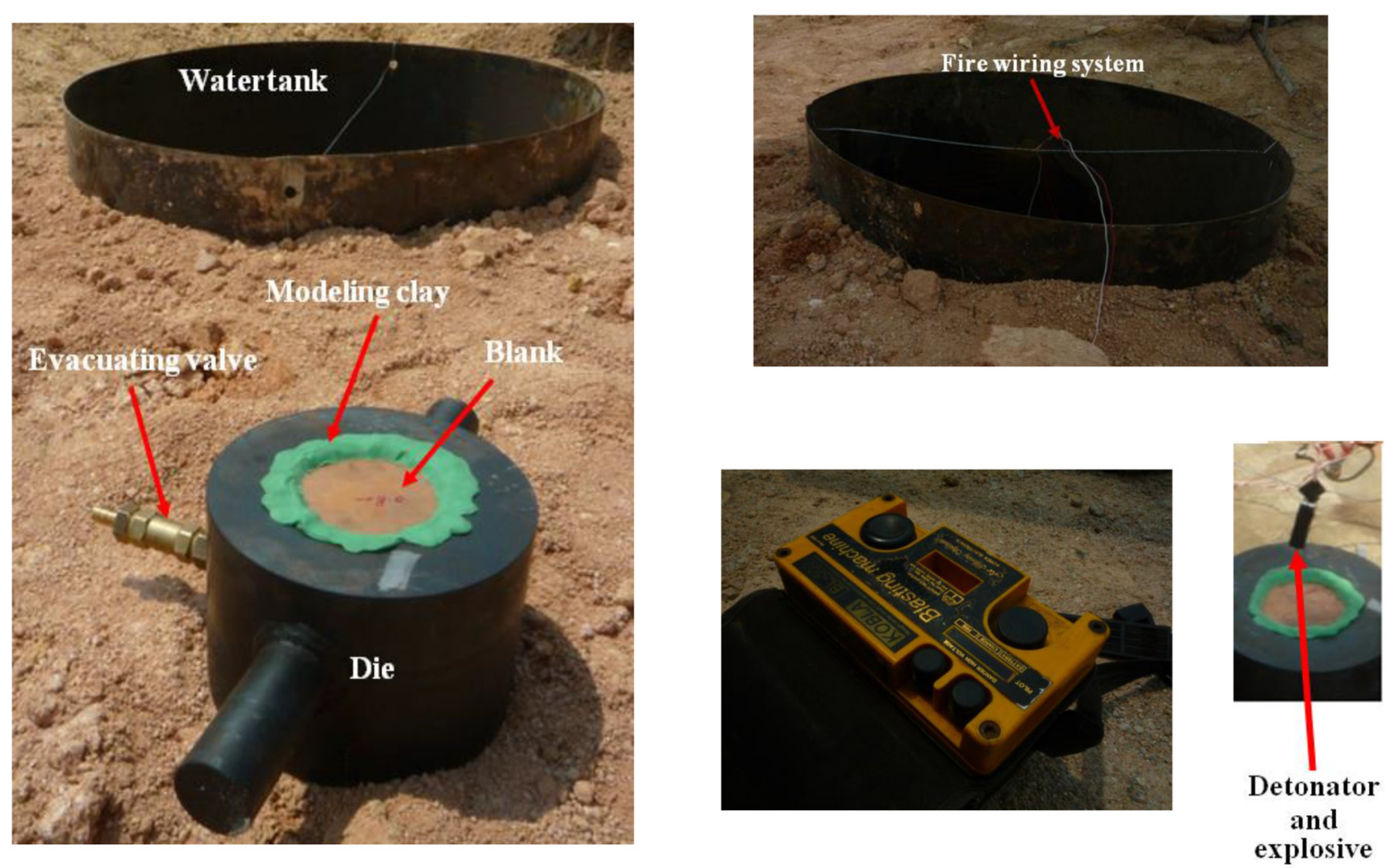

Fig. 4. Facilities of experiments.

Table 2. Experimental plan and codes.

\begin{tabular}{lllllll}
\hline Trial no & Experiment codes & Material & $t_{0}(\mathrm{~mm})$ & $D_{0}(\mathrm{~mm})$ & $\theta$ (degree) & $S_{d}(\mathrm{~mm})$ \\
\hline 1 & Cu-L-S-W-1 & Cu-ETP & 0.8 & 100 & 60 & 130 \\
2 & Cu-M-S-W-2 & Cu-ETP & 1 & 100 & 60 & 150 \\
3 & Cu-H-S-W-3 & Cu-ETP & 1.2 & 100 & 60 & 170 \\
4 & Cu-L-B-O-1 & Cu-ETP & 0.8 & 110 & 45 & 130 \\
5 & Cu-M-B-O-2 & Cu-ETP & 1 & 110 & 45 & 150 \\
6 & Cu-H-B-O-3 & Cu-ETP & 1.2 & 110 & 45 & 170 \\
7 & St-L-S-W-2 & AISI 1006 & 0.8 & 100 & 60 & 150 \\
8 & St-M-S-W-3 & AISI 1006 & 1 & 100 & 60 & 130 \\
9 & St-H-S-W-1 & AISI 1006 & 1.2 & 100 & 60 & 130 \\
10 & St-L-B-O-2 & AISI 1006 & 0.8 & 110 & 45 & 170 \\
11 & St-M-B-O-3 & AISI 1006 & 1 & 110 & 45 & 130 \\
12 & St-H-B-O-1 & AISI 1006 & 1.2 & 110 & 45 & 130 \\
13 & Al-L-S-W-3 & 6061-O Al & 0.8 & 100 & 60 & 130 \\
14 & Al-M-S-W-1 & 6061-O Al & 1 & 100 & 60 & 150 \\
15 & Al-H-S-W-2 & $6061-O$ Al & 1.2 & 100 & 60 & 130 \\
16 & Al-L-B-O-3 & $6061-O$ Al & 0.8 & 110 & 45 & 45 \\
17 & Al-M-B-O-1 & $6061-O$ Al & 1 & 110 & 45 & 150 \\
18 & Al-H-B-O-2 & $6061-O$ Al & 1.2 & 110 & & \\
\hline
\end{tabular}




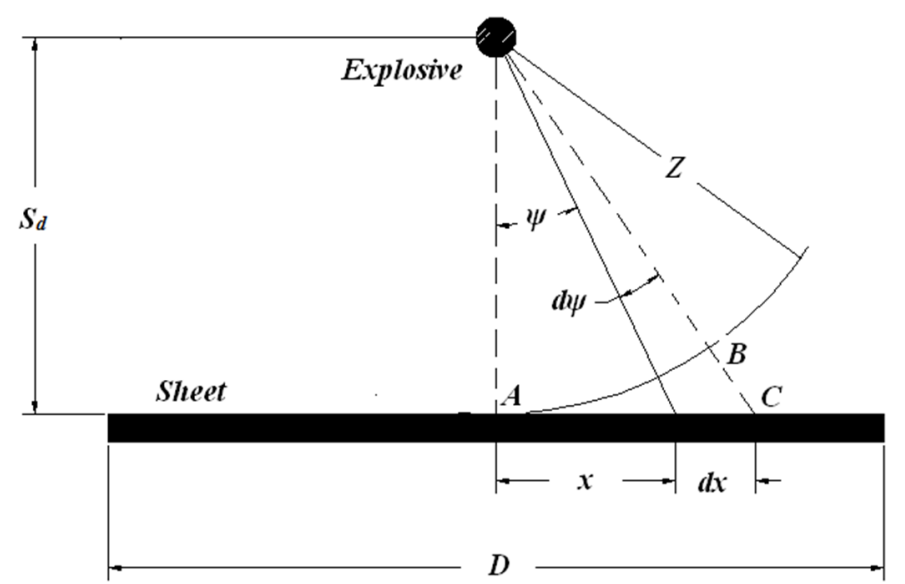

Fig. 5. Impulse transmitted from the explosive to the circular sheet.

and acts as the effective factor in forming the blank during explosive forming operation [61]. Hence, $I_{n}$ needs to be calculated to estimate the explosive mass required for forming the blank into the cone. Figure 5 shows an explosive on a given standoff from a circular sheet with the diameter $D$.

Based on Figure 5, the impulse content of element $A B$ from the shockwave is transferred to the element $A C$ of the sheet and gives it a perpendicular velocity. The total impulse of element $A B$ (this impulse makes the angle $\psi$ with the normal vector of sheet) is given as the following equation.

$$
I_{t}^{\prime}=\frac{\beta W^{\frac{\varphi+1}{3}}}{S_{d}^{\varphi}} A B
$$

Therefore, the normal component of this impulse can be defined as

$$
I_{t n}^{\prime}=\frac{\beta W^{\frac{\varphi+1}{3}}}{S_{d}^{\varphi}} A B \cos \psi
$$

Consequently, the intensity of impulse per unit area which is perpendicular to the element $A C$ can be translated as

$$
I_{(t n) A C}^{\prime}=\frac{\beta W^{\frac{\varphi+1}{3}}}{S_{d}^{\varphi}}\left(\frac{A B}{A C}\right) \cos \psi=\frac{\beta W^{\frac{\varphi+1}{3}}}{S_{d}^{\varphi}} \cos ^{2} \psi
$$

Hence, the impulse perpendicular to an annular element with radius $x$ and width $d_{x}$ can be obtained in the form of

$$
d I_{n}^{\prime}=\frac{\beta W^{\frac{\varphi+1}{3}}}{S_{d}^{\varphi}}(2 \pi x d x) \cos ^{2} \psi
$$

Thus, the total perpendicular impulse to the sheet, $I_{n}$, can be derived integrating equation (5) which gives

$$
I_{n}=2 \pi \beta W^{\frac{\varphi+1}{3}} \int_{0}^{(D / 2)} \frac{x}{Z^{\varphi}} \cos ^{2} \psi d x
$$

Considering the geometrical configuration in Figure 5 and for small amount of $\psi$

$$
\cos ^{2} \psi=\frac{S_{d}^{2}}{x^{2}+S_{d}^{2}}
$$

and likewise

$$
Z=\sqrt{\left(x^{2}+S_{d}^{2}\right)}
$$

By substituting equations (7) and (8) into equation (6) the perpendicular impulse can be derived as

$$
I_{n}=2 \pi \beta W^{\frac{\varphi+1}{3}} S_{d}^{2} \int_{0}^{(D / 2)} \frac{x}{\left(x^{2}+S_{d}^{2}\right)^{(\varphi / 2)+1}} d x
$$

Finally, integrating the integration term of equation (9) yields

$$
\begin{aligned}
I_{n}= & 2 \pi \beta W^{\frac{\varphi+1}{3}} D^{2-\varphi}\left(\frac{S_{d}}{D}\right)^{2} \frac{1}{\varphi} \\
& \times\left[\frac{1}{\left(S_{d} / D\right)^{\varphi}}-\frac{1}{\left(\left(S_{d} / D\right)^{2}+0.25\right)^{\varphi / 2}}\right]
\end{aligned}
$$

\subsection{Determination of forming strain energy}

Based on the definition of plastic work, the differential amount of ideal strain energy per volume unit, $d u$, can be expressed as [63]

$$
d u=\sigma_{1} d \varepsilon_{1}+\sigma_{2} d \varepsilon_{2}+\sigma_{3} d \varepsilon_{3}
$$

where $\sigma 1, \sigma 2$ and $\sigma 3$ are principal stresses and $\varepsilon 1, \varepsilon 2$ and $\varepsilon 3$ are principal strains. Also, the effective stress-strain function is expressed such that the incremental strain energy per volume unit is

$$
d u=\sigma_{e f f} d \varepsilon_{e f f}
$$

where $\sigma_{\text {eff }}$ and $\varepsilon_{\text {eff }}$ are effective stress and effective strain, respectively. In modeling of the manufacturing process, it is often essential to determine the flow stress of the material. The concept of effective stress is to have a yield criterion so that the yield phenomenon takes place when the magnitude of $\sigma_{\text {eff }}$ attains a critical amount. By von Mises criterion, $\sigma_{\text {eff }}$ can be determined as [66]

$$
\sigma_{e f f}=\sqrt{(1 / 2)\left[\left(\sigma_{1}-\sigma_{2}\right)^{2}+\left(\sigma_{2}-\sigma_{3}\right)^{2}+\left(\sigma_{1}-\sigma_{3}\right)^{2}\right]}
$$

The von Mises effective strain can be described as [62]

$$
d \varepsilon_{e f f}=\frac{\sqrt{2}}{3}\left[\left(d \varepsilon_{1}-d \varepsilon_{2}\right)^{2}+\left(d \varepsilon_{2}-d \varepsilon_{3}\right)^{2}+\left(d \varepsilon_{1}-d \varepsilon_{3}\right)^{2}\right]^{\frac{1}{2}}
$$




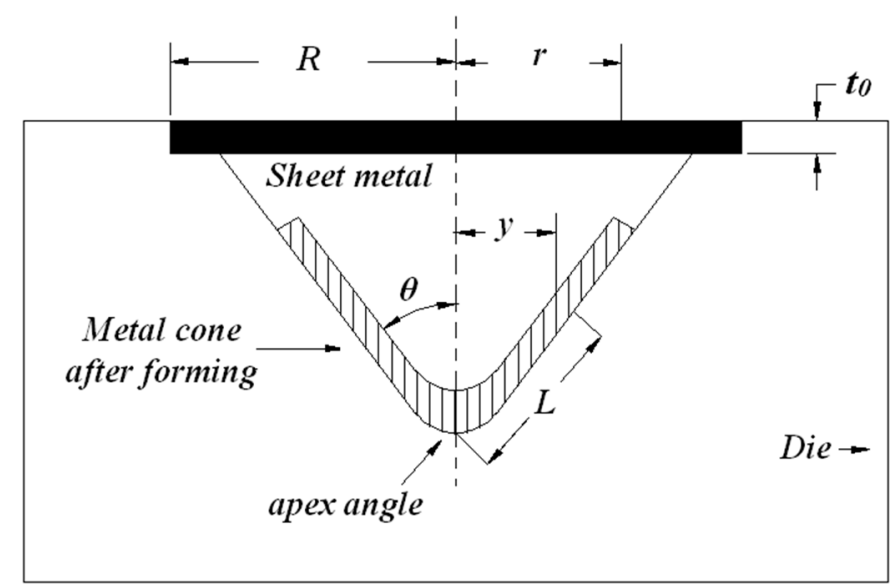

Fig. 6. schematic for forming circular sheet metal into a cone.

or in a simpler form

$$
\varepsilon_{e f f}=\sqrt{(2 / 3)\left(\varepsilon_{1}^{2}+\varepsilon_{2}^{2}+\varepsilon_{3}^{2}\right)}
$$

Ignoring the effect of strain hardening effect and considering equation (13), it can be expressed that

$$
\sigma_{e f f}=\sigma_{y_{0}}
$$

in which $\sigma y_{0}$ is the yield strength of the material. Substituting equation (16) in equation (12) and integrating

$$
u=\sigma_{y_{0}} \varepsilon_{e f f}
$$

The total ideal strain energy for forming, $U_{I}$, is the volume integration of equation (17). Therefore,

$$
U_{I}=\int u d V
$$

in which, $V$ is the volume of sheet metal.

Now, it is necessary to present an analytical model to estimate the amount of strain energy required for cone forming $(U)$. Here, to simplify the calculation of $U$ two assumptions are considered: (1) the thickness of samples remains constant during the forming process. (2) The effect of strain hardening is neglected (using a rigid-perfectly plastic constitutive model). Based on these assumptions, a model is established to estimate the amount of $U$ for forming a metal cone. This analytical model leads to determine the relationship among parameters contributed to the setup configuration for explosive forming of the cone. Figure 6 shows a schematic of converting a circular blank into a cone during the forming process. From Figure 6, it is observed that, after finishing the forming process, the area of sheet metal with the radius of $r$ is converted to the area of cone with the slant height of $L$ and radius base of $y$. Therefore, given that the volume of sheets remains constant during plastic deformation, isochoric plastic deformation [67], it can be expressed that

$$
\pi y L=\pi r^{2}
$$

From Figure 6 and considering the geometry

$$
L=y / \sin \theta
$$

By combining equations (19) and (20)

$$
\sin \theta=\frac{y^{2}}{r^{2}}
$$

On the other hand, circumferential strain, $\varepsilon_{a}$, in the edge of cone base can be expressed as

$$
\varepsilon_{a}=\ln \left(\frac{y}{r}\right)
$$

Incorporating equations (21) and (22), equation (23) is generated as

$$
\varepsilon_{a}=\frac{1}{2} \ln (\sin \theta)
$$

Considering the isochoric plastic deformation, the summation of circumferential, slant strain $\left(\varepsilon_{L}\right)$ and thickness strain $\left(\varepsilon_{t}\right)$ are equals to zero, or

$$
\varepsilon_{a}+\varepsilon_{L}+\varepsilon_{t}=0
$$

Since thickness is assumed constant during the forming process, it can be written that

$$
\varepsilon_{t}=\ln \frac{t}{t_{0}}=0
$$

where $t$ is the thickness of the sample at the end of forming process. Replacing equation (25) in equation (24)

$$
\varepsilon_{a}=-\varepsilon_{L}
$$

By substituting equations (25) and (26) into equation (14), it can be expressed that

$$
\varepsilon_{e f f}=\frac{\sqrt{2}}{3}\left[\left(\left(\varepsilon_{a}-\left(-\varepsilon_{L}\right)\right)^{2}+\varepsilon_{a}^{2}+\varepsilon_{a}^{2}\right]^{\frac{1}{2}}\right.
$$

Thus, the effective strain for forming the blank into the cone is derived as

$$
\varepsilon_{e f f}=\frac{2}{\sqrt{3}}\left|\varepsilon_{a}\right|
$$

Incorporating equations (23) and (28) and putting the result into equation (17), the strain energy per volume unit can be express as

$$
u=\frac{\sigma_{y_{0}}}{\sqrt{3}} \ln \left(\frac{1}{\sin \theta}\right)
$$

By substituting equation (29) into equation (18) and after volume integration, the ideal strain energy for forming can be obtained as

$$
U_{I}=\frac{\sqrt{3} \pi R^{2} t_{0} \sigma_{y_{0}}}{3} \ln \left(\frac{1}{\sin \theta}\right)
$$

where $R$ is the radius of sheet before forming process. 


\subsection{Effect of strain rate}

Although the effect of strain rate in low rate forming is constant temperature is negligible, however increasing the loading rate by a factor of 250000 at a constant temperature may enhance the flow stress by 3 times or more [68]. Therefore, the flow stress of metals at a very high loading rate, for example, explosive loading is dramatically changed even at room temperature [69]. For a broad range of materials, the effect of strain rate on the flow stress $(\sigma)$ at a certain temperature and strain may be expressed by a power-law description [70]

$$
\sigma=q \dot{\varepsilon}^{n}
$$

where $q$ and $n$ are the material parameters and the exponent, $n$, is named the strain rate sensitivity. The relative levels of flow stress, $\gamma$, at two different strain rates, given at the equivalent total strain, is expressed by [63]

$$
\gamma=\frac{\sigma_{y}}{\sigma_{y_{0}}}=\left(\frac{\dot{\varepsilon}}{\dot{\varepsilon}_{0}}\right)^{n}
$$

where $\varepsilon^{\prime}$ and $\varepsilon_{0}$ are the strain rates corresponding to flow stresses $\sigma_{y}$ (dynamic flow stress) and $\sigma y_{0}$ (static flow stress), respectively. Considering that $\sigma y_{0}$ is the static yield strength of material and accessible via tensile test, $\sigma_{y}$ can be achieved through the following equation.

$$
\sigma_{y}=\gamma \sigma_{y_{0}}
$$

In better word $\gamma$ is the "ratio of dynamic to static flow stress" [71]. In the case of most metals, the certain results of $n$ and $\gamma$, especially in very high rate loading processes such as explosive loading, have been rarely published. The range of $\gamma$ has been estimated between 1.5 and 3 dependent on the material type [62,72,73]. However, in some references [74], the amount of $\gamma$ for low carbon steel and copper has been reported around 2 and 1.83 , respectively. The average strain rate during most tensile tests is in the range of $10^{-3} \mathrm{~s}^{-1}$ to $10^{-2} \mathrm{~s}^{-1}$ [63], while it is around $10^{7} \mathrm{~s}^{-1}$ in explosive loading processes [75]. Also, parameter $n$ for aluminum has been reported near 0.025 in some references [62]. Considering equation (32) and the reported amount of $n$, the value of $\gamma$ can be estimated at around 1.78 for aluminum. Hence, the effect of strain rate on the ideal strain energy of forming can be contributed by replacing equation (33) into equation (30) and expressed as

$$
U_{I}=\frac{\sqrt{3} \pi R^{2} t_{0} \gamma \sigma_{y_{0}}}{3} \ln \left(\frac{1}{\sin \theta}\right)
$$

\subsection{Effect of friction and redundant work}

Equation (34) gives an estimation of strain energy in which, ideal process is envisioned to obtain a favorable shape change. It means this estimation represents the minimum strain energy required for forming. However, since the ideal forming process not to be physically feasible, the explosive load needs to supply the multiple sorts of work required in the explosive forming process. Besides the ideal work, there are two other works against (1) friction between sheet metal and die and (2) work to carry out redundant or unwelcome forming [76]. Therefore, the total energy of a forming process, $U$, can be considered as the energy to overcome the sum of ideal, frictional and redundant energies. This can be express as [77]

$$
U=U_{I}+U_{f}+U_{r}
$$

where $U_{f}$ and $U_{r}$ are the energies consumed by friction, and redundant works, respectively. Since it is difficult to present an explicit description for $U_{f}$ and $U_{r}$, the total effect of them is normally defined as a term called "deformation efficiency", $\eta$ [62], where

$$
\eta=\frac{U_{I}}{U}
$$

and thus, the total strain energy for the forming process can be expressed via the following equation.

$$
U=\frac{U_{I}}{\eta}
$$

Although explosive forming parameters, for example, geometry or apex angle of die and friction ratio influence on the value of $\eta$, however determining of this is much difficult. Empirical surveys allow making a reasonable estimate of $\eta$ for some conventional metal forming processes. It has been reported in the range of 0.5 and 0.65 based on lubrication condition, reduction, and die angle [62]. In this research, due to the high explosive compressive load and absence of lubrication which both lead to increase friction, the primary estimation of $\eta$ is considered the average value means 0.575 . Hence, replacing equation (37) in equation (34), the total strain energy for cone forming $(U)$ can be expressed as

$$
U=\frac{\sqrt{3} \pi R^{2} t_{0} \gamma \sigma_{y_{0}}}{3 \eta} \ln \left(\frac{1}{\sin \theta}\right)
$$

\subsection{Estimation of explosive mass}

As mentioned in Section 5.1.1, the UNDEX shockwave gives the sheet metal a perpendicular impulse $\left(I_{n}\right)$. This perpendicular impulse gives the sheet metal a perpendicular velocity which provides the kinetic energy required for forming the sheet metal into a cone. According to the conservation of linear momentum [78], the perpendicular velocity can be reasonably assumed constant during the forming process. Due to this velocity, the kinetic energy required for forming can be expressed as

$$
U=\frac{1}{2} m v^{2}
$$

where $m$ and $v$ are the sheet metal mass and velocity, respectively. The amount of $U$ is estimated by 


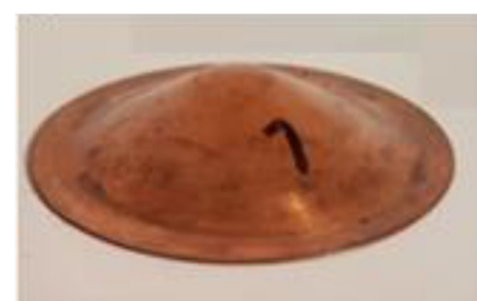

$\mathrm{Cu}-\mathrm{H}-\mathrm{S}-\mathrm{W}-1$

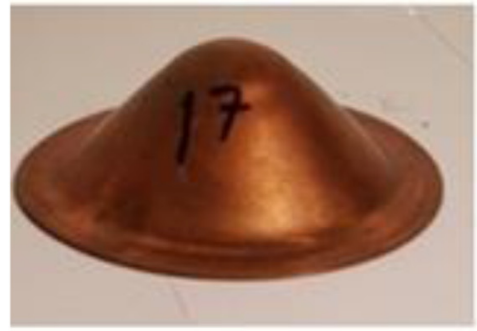

$\mathrm{Cu}-\mathrm{M}-\mathrm{B}-\mathrm{O}-2$

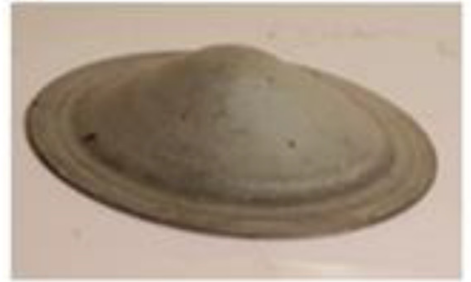

St-M-S-W-3

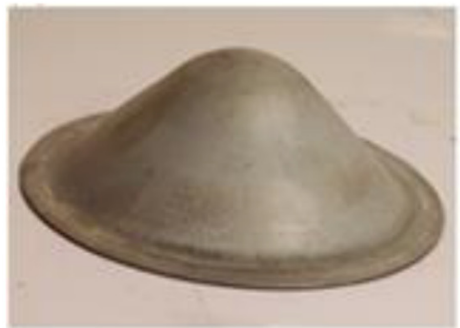

St-L-B-O-2

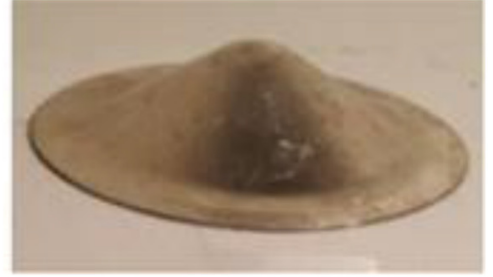

Cu-H-S-W-2

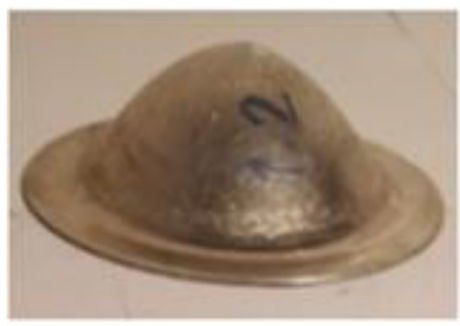

Al-M-B-O-2

Fig. 7. Experimental deformation modes for some samples.

equation (38). As a result, velocity can be presented as

$$
v=\left(\frac{2 U}{m}\right)^{\frac{1}{2}}
$$

The impulse required for forming, $I_{s h}$ can be calculated as [79]

$$
I_{s h}=m v
$$

Replacing equation (41) into equation (40), $I_{s h}$ can be calculated as

$$
I_{s h}=(2 m U)^{\frac{1}{2}}
$$

Equating the impulse required for forming $\left(I_{s h}\right)$ and the impulse received by the sheet metal blank due to UNDEX $\left(I_{n}\right)$, it can be expressed that

$$
I_{s h}=I_{n}
$$

By substituting equations (10) and (42) in both sides of the equation (43) the explosive mass required for forming a cone is estimated as

$$
\begin{aligned}
W= & \left\{\frac{1}{2} \pi \beta(2 R)^{2-\varphi}\left(\frac{S_{d}}{R}\right)^{2} \frac{1}{\varphi}\right. \\
& \left.\times\left[\frac{1}{\left(S_{d}-2 R\right)^{\varphi}}-\frac{1}{\left(\left(S_{d} / 2 R\right)^{2}+(1 / 4)\right)^{\varphi / 2}}\right] I_{s h}^{-1}\right\}^{\frac{3}{\varphi+1}}
\end{aligned}
$$

\section{Results and discussion}

Results of the theoretical model were run for various explosive forming conditions including sample thickness, diameter and material, standoff and die apex angle to understand the critical differences between the predicted and experimental results. Discussion on these results is extended to the effect of deformation efficiency and strain rate parameters on the estimation of explosive mass. Modification of the model was carried out to achieve better agreement between the prediction model and the actual experimental results. The acceptable equation was verified at a different standoff to ensure its robustness.

\subsection{Validation of analytical equation}

Figure 7 shows the experimental deformation modes of samples into the cone, for some trials carried out in this research. To ascertain whether the analytical equation is sufficiently accurate to estimate the explosive mass required for cone forming, it has been validated using results from experiments. The relative error between analytical and experimental results is determined and the reasons for errors are discussed.

\subsection{Analytical and experimental results of explosive mass}

The analytical and experimental values of explosive mass required for all trials presented in this study are tabulated in Table 3. Moreover, for further understanding and comparison, these results are depicted in Figure 8.

Figures $8 \mathrm{a}-8 \mathrm{c}$ show analytical and experimental explosive mass required for copper, steel and aluminum samples, respectively. By referring to Table 3 and these figures, it is noteworthy that for all trials used in this study, the analytical results are lower than the experimental results. This common discord between these two results can be attributed to the several possible factors contributing to the explosive mass estimation method which will be discussed in the following. As mentioned earlier, the analytical model presented in this study has been 
Table 3. Analytical and experimental results of explosive mass.

\begin{tabular}{lllllllr}
\hline Trial no & Samples Code & $t_{0}(\mathrm{~mm})$ & $D_{0}(\mathrm{~mm})$ & $\theta$ (degree) & $S_{d}(\mathrm{~mm})$ & \multicolumn{2}{c}{ Explosive mass $(\mathrm{gr})$} \\
\cline { 6 - 7 } & & & & & & Analytical & Experimental \\
\hline 1 & Cu-L-S-W-1 & 0.8 & 100 & 60 & 130 & 2.60 & 3.15 \\
2 & Cu-M-S-W-2 & 1 & 100 & 60 & 150 & 4.35 & 5.40 \\
3 & Cu-H-S-W-3 & 1.2 & 100 & 60 & 170 & 6.73 & 8.40 \\
4 & Cu-L-B-O-1 & 0.8 & 110 & 45 & 130 & 5.23 & 6.50 \\
5 & Cu-M-B-O-2 & 1 & 110 & 45 & 150 & 8.67 & 10.75 \\
6 & Cu-H-B-O-3 & 1.2 & 110 & 45 & 170 & 13.36 & 16.50 \\
7 & St-L-S-W-2 & 0.8 & 100 & 60 & 150 & 3.60 & 4.55 \\
8 & St-M-S-W-3 & 1 & 100 & 60 & 170 & 5.93 & 7.50 \\
9 & St-H-S-W-1 & 1.2 & 100 & 60 & 130 & 5.59 & 7.00 \\
10 & St-L-B-O-2 & 0.8 & 110 & 45 & 150 & 7.19 & 9.20 \\
11 & St-M-B-O-3 & 1 & 110 & 45 & 170 & 11.77 & 15.15 \\
12 & St-H-B-O-1 & 1.2 & 110 & 45 & 130 & 11.22 & 14.50 \\
13 & Al-L-S-W-3 & 0.8 & 100 & 60 & 170 & 0.67 & 0.85 \\
14 & Al-M-S-W-1 & 1 & 100 & 60 & 130 & 0.67 & 0.90 \\
15 & Al-H-S-W-2 & 1.2 & 100 & 60 & 150 & 1.06 & 1.35 \\
16 & Al-L-B-O-3 & 0.8 & 110 & 45 & 170 & 1.33 & 1.60 \\
17 & Al-M-B-O-1 & 1 & 110 & 45 & 130 & 1.35 & 1.65 \\
18 & Al-H-B-O-2 & 1.2 & 110 & 45 & 150 & 2.10 & 2.50 \\
\hline
\end{tabular}

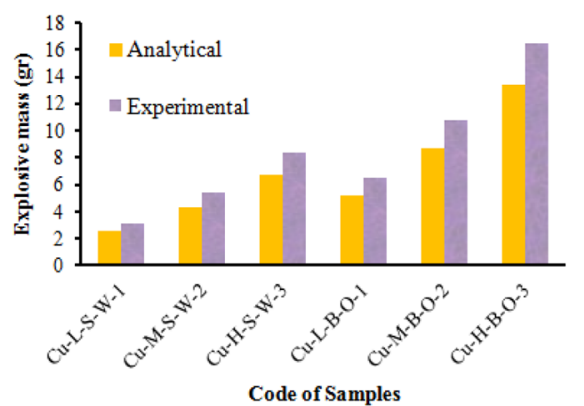

(a)

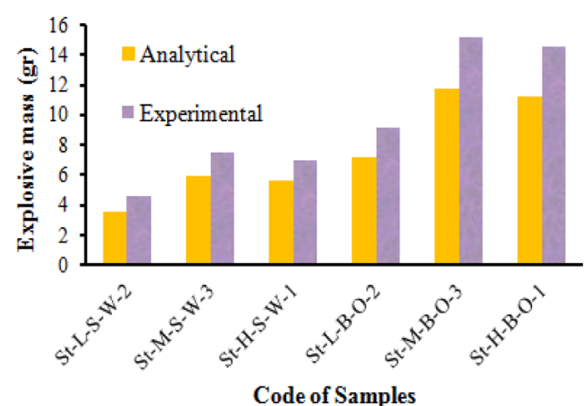

(b)

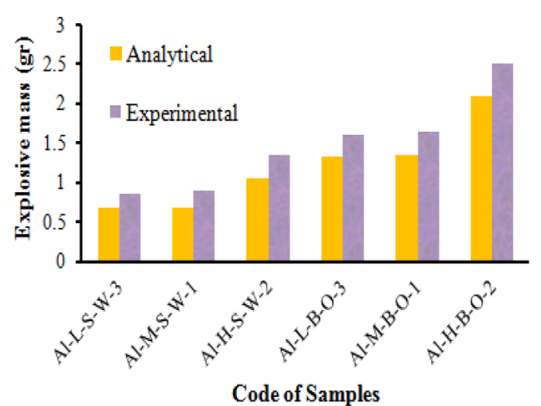

(c)

Fig. 8. Analytical and experimental explosive mass for (a) copper, (b) steel, (c) aluminum samples.

established based on two assumptions: first, the thickness of samples remains constant during the forming process and second, the effect of strain hardening is neglected. While thickness is assumed constant during the forming process, the term which describes the thickness strain equals zero. As the result, the value of equivalent plastic strain and consequently strain energy estimated through Equation (38) decreases. Hence, the estimated value of explosive mass which is directly influenced by the strain energy declines. There is a similar justification for the second assumption i.e., neglecting the effect of strain hardening which leads to the lower estimation of required plastic work for the perfect forming of a cone. Besides, one must bear in mind that the impulse method employed for explosive mass prediction presents a lower bound estimate based on empirical pressure and it does not comprise the effect of the reloading phase [80]. Therefore, it leads to a slightly higher estimation of explosive mass in this process and this higher estimation of explosive mass that assists to compensate for the effects of assumptions which cause to lower estimation of strain energy.

In addition to the aforementioned assumptions, the effect of friction, redundant work and strain rate in the analytical model was contributed through a constant coefficient extracted from the literature. Since these coefficients are the approximation of real forming conditions, employing them leads to occur error in explosive mass estimation. The effectiveness of these coefficients on the explosive mass estimation through the analytical method is more discussed in Section 6.5. 
Table 4. REPs of analytical estimated explosive mass in comparison with the experimental results.

\begin{tabular}{llccc}
\hline \multirow{2}{*}{ Trial no } & Samples code & \multicolumn{2}{c}{ Explosive weight (gr) } & $\begin{array}{c}\text { REP for analytical to } \\
\text { experimental }(\%)\end{array}$ \\
\cline { 3 - 4 } & & Analytical & Experimental & 21.15 \\
2 & Cu-L-S-W-1 & 2.60 & 3.15 & 24.14 \\
3 & Cu-M-S-W-2 & 4.35 & 5.40 & 24.81 \\
4 & Cu-H-S-W-3 & 6.73 & 8.40 & 24.28 \\
5 & Cu-L-B-O-1 & 5.23 & 6.50 & 23.99 \\
6 & Cu-M-B-O-2 & 8.67 & 10.75 & 23.50 \\
7 & Cu-H-B-O-3 & 13.36 & 16.50 & 26.39 \\
8 & St-L-S-W-2 & 3.60 & 4.55 & 26.48 \\
9 & St-M-S-W-3 & 5.93 & 7.50 & 25.22 \\
10 & St-H-S-W-1 & 5.59 & 7.00 & 27.96 \\
11 & St-L-B-O-2 & 7.19 & 9.20 & 28.72 \\
12 & St-M-B-O-3 & 11.77 & 15.15 & 29.23 \\
13 & St-H-B-O-1 & 11.22 & 14.50 & 25.86 \\
14 & Al-L-S-W-3 & 0.67 & 0.85 & 21.50 \\
15 & Al-M-S-W-1 & 0.67 & 0.90 & 27.36 \\
16 & Al-H-S-W-2 & 1.06 & 1.35 & 20.30 \\
17 & Al-L-B-O-3 & 1.33 & 1.60 & 22.22 \\
18 & Al-M-B-O-1 & 1.35 & 1.65 & 19.05 \\
\hline
\end{tabular}

\subsection{Error of analytical results}

The values of Relative Error Percentage (REP) of estimated explosive mass, obtained from the analytical equation in comparison with experimental results are listed in Table 4. From this table, the mean value of REP for analytical results is around $24.56 \%$ with the standard division of 2.92. As mentioned earlier, the simplifications and assumptions employed in establishing an analytical model led to the error occurring in the estimation of explosive mass. It is also observed that the REP of the analytical model for copper samples is $23.65 \%$ with the standard division of 1.29. Likewise, the REPs of the analytical model for the steel and aluminum samples are $27.33 \%$ and $22.72 \%$ with the standard divisions of 1.33 and 3.24 , respectively.

The difference between the mean values of REPs for different materials attributes to neglect the effect of strain hardening during the plastic deformation of samples. As the matter of fact, the analytical model describes the plastic deformation of all material samples in similar behavior (rigid-perfectly plastic), while it varies from one material to another. This variation is observable considering Figure 3. From this figure, it is obvious that, the strain hardening of AISI 1006 is more than Cu-ETP in the plastic area. Also, Cu-ETP shows more hardening behavior than 6061-O Al during plastic deformation. As it is known, increasing the strain hardening of the material leads to increase the plastic work for the forming process [63]. Therefore, the differences among REPs of samples used in this study can be explained this way: a material with more strain hardening needs more energy to accomplish the forming process. Thus, the mean value of REP for steel samples is more than $\mathrm{Cu}$-ETP. Likewise, the minimum value of the REP belongs to 6061-O Al.

\subsection{Effects of deformation efficiency and strain rate variations}

As mentioned in Section 5.2, two main assumptions used to establish the analytical model, that is, assuming no changes in the sample thickness during the forming process and ignoring the effect of strain hardening, lead to occur the error in the obtained analytical results for the explosive mass required for forming process. However, the absence of these simplifier assumptions makes the development of the analytical model cumbersome. For example, to import the wall thickness variations in mass computations, it must be investigated through a detailed experimental or numerical analysis and a functional pattern needs to be established for this issue. In the case of strain hardening, considering the diversity of models for hardening behavior of materials during the plastic deformation, a very comprehensive experimental study needs to be designed and implemented. Therefore, the effects of these assumptions can be separately investigated as future studies.

On the other hand, the effects of friction and redundant work on the analytical model were described through the concept of deformation efficiency with the symbol $\eta$. Likewise, the ratio of dynamic to static flow stress, $\gamma$, was contributed to the analytical model for considering the effect of strain rate. Circumstances of employing these two dimensionless quantities in developing the analytical method were explained in detail in the Sections 5.3 and 5.4. 


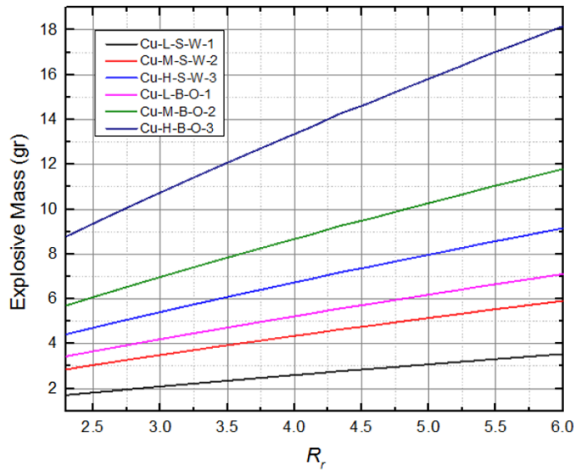

(a)

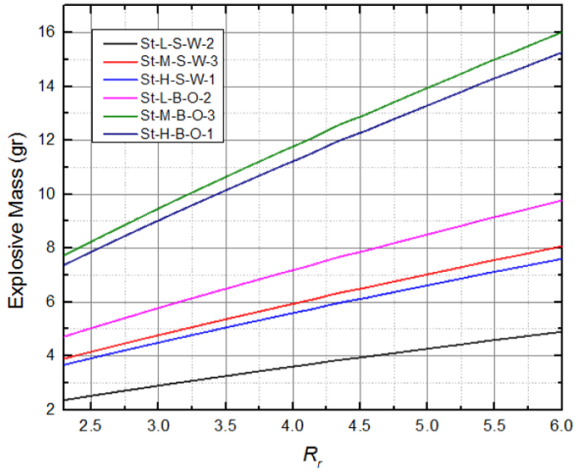

(b)

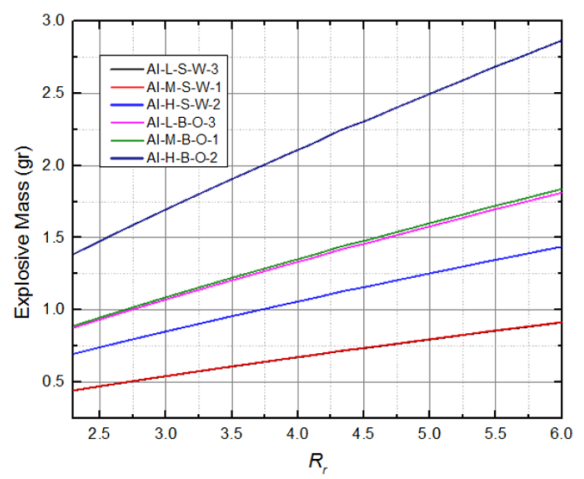

(c)

Fig. 9. Variations of estimated explosive mass vs. $R r$ for (a) copper, (b) steel and (c) aluminum samples.

Since the deformation efficiency and strain rate are independent of each other, investigation of the simultaneous effect of them on the explosive mass may requires complicated experimental or statistical methods. However, considering equation (38), the effects of these two parameters on the strain energy is linear. In this equation, $\gamma$ is in the numerator and $\eta$ is in the denominator. Dividing these two parameters, another dimensionless parameter, here nominated Robustness ratio $\left(R_{r}\right)$, is achieved that can be given as

$$
R_{r}=\frac{\gamma}{\eta}
$$

By replacing equation (45) into equation (38), the total strain energy for cone forming process can be expressed as

$$
U=\frac{\sqrt{3} \pi R^{2} t \sigma_{y_{0}}\left(R_{r}\right)}{3} \ln \left(\frac{1}{\sin \theta}\right)
$$

Thus, the effect of $R_{r}$ on the explosive mass may be considered as an alternative for deformation efficiency and strain rate.

According to the literature, a range of variations for $\gamma$ has been suggested between 1.5 and 3, depending on the material type and rate of loading. Likewise, $\eta$ is generally estimated in the range of $0.5-0.65$ based on forming conditions. According to the abovementioned and considering the approximated values of $\gamma$ and $\eta$, the initial estimations of $R_{r}$ were $3.18,3.48$ and 3.10 for copper, steel and aluminum samples, respectively. However, noting the lower and upper bound values of $\gamma$ and $\eta$, the $R_{r}$ can be varied between 2.31 and 6 . Figure 9 shows the variation of explosive mass obtained from the analytical equation versus the variation of $R_{r}$ for different sample materials.

From Figure 9, it is obvious that the effect of $R_{r}$ variations on the explosive mass is linear. This issue seems logical since the effects of $\gamma$ and $\eta$ on the strain energy obtained via equation (38) were as well linear. The main advantage of these graphs is to find a value for $R_{r}$ in which the amount of explosive mass obtained from the analytical model equals to that than of the experiments.

Figure 9 also shows that practically the value of $R_{r}$ is always higher than that of initial estimation for the analytical model. This can be observed for all trials implemented in this research. This issue roots into two reasons: first, using the simplifications to establish the analytical model causing to decrease the strain energy estimation. Thus, to compensate for the effects of these simplifications, a higher estimation of $R_{r}$ needs to be carried out. Second, the effects of strain rate and deformation efficiency on the forming process are far more than those of the initial estimation employed in the analytical model. In the case of both points of view, $R_{r}$ may able to play a role in achieving a better estimation of explosive mass required for the complete forming process.

The values of initial estimation, modified estimation and the Mean Value for Modified Estimation (MVME) of $R_{r}$ for each trial have been tabulated in Table 5 . The modified estimation is a value of $R_{r}$ in which the amount of explosive mass obtained from the analytical model becomes equivalent to that of the experiments. The MVME is the average of the modified estimation of $R_{r}$ based on the material samples.

From Table 5, it is obvious that the difference among the modified estimation values of $R_{r}$ for all trials regarding a certain material sample is negligible. Therefore, for each material, the value of MVME may be substituted instead of a modified estimation of $R_{r}$. This issue is more justified by observing the standard divisions of MVME which are $0.076,0.065$ and 0.049 for copper, steel and aluminum samples, respectively.

From Table 5 , it also seems that the value of $R_{r}$ more pertains to the material sample instead of the geometrical configuration of the forming process. It is justified this way: the value of $R_{r}$ is calculated from division of $\gamma$ to $\eta$. The value of $\gamma$ for a certain material just depends on the strain rate or rate of loading during plastic deformation [81]. Since all trials are implemented in a near-constant loading rate (explosion condition), the value of $\gamma$ is just dependent on material samples. Likewise, the value of $\eta$ is most related to friction and redundant work [82]. As well, the redundant work is influenced intensively by friction [62]. Indeed, plastic deformations during the forming process come to pass with friction at the sample-die interface. This friction causes inhomogeneous deformation due to additional shear and thus, the redundant work increases. Since the value of friction in a surface-to-surface interaction is rather 
Table 5. Initial estimation, modified estimation and MVME for $R_{r}$.

\begin{tabular}{|c|c|c|c|c|}
\hline \multirow[t]{2}{*}{ Trial no } & \multirow[t]{2}{*}{ Samples code } & \multicolumn{3}{|c|}{$R_{r}$} \\
\hline & & Initial estimation & Modified estimation & MVME \\
\hline 1 & Cu-L-S-W-1 & \multirow{6}{*}{3.18} & 5.14 & \multirow{6}{*}{5.29} \\
\hline 2 & $\mathrm{Cu}-\mathrm{M}-\mathrm{S}-\mathrm{W}-2$ & & 5.32 & \\
\hline 3 & Cu-H-S-W-3 & & 5.35 & \\
\hline 4 & Cu-L-B-O-1 & & 5.33 & \\
\hline 5 & $\mathrm{Cu}-\mathrm{M}-\mathrm{B}-\mathrm{O}-2$ & & 5.31 & \\
\hline 6 & $\mathrm{Cu}-\mathrm{H}-\mathrm{B}-\mathrm{O}-3$ & & 5.29 & \\
\hline 7 & St-L-S-W-2 & \multirow{6}{*}{3.48} & 5.43 & \multirow{6}{*}{5.49} \\
\hline 8 & St-M-S-W-3 & & 5.44 & \\
\hline 9 & St-H-S-W-1 & & 5.41 & \\
\hline 10 & St-L-B-O-2 & & 5.54 & \\
\hline 11 & St-M-B-O-3 & & 5.56 & \\
\hline 12 & St-H-B-O-1 & & 5.53 & \\
\hline 13 & Al-L-S-W-3 & \multirow{6}{*}{3.10} & 4.44 & \multirow{6}{*}{4.47} \\
\hline 14 & Al-M-S-W-1 & & 4.51 & \\
\hline 15 & Al-H-S-W-2 & & 4.41 & \\
\hline 16 & Al-L-B-O-3 & & 4.47 & \\
\hline 17 & Al-M-B-O-1 & & 4.44 & \\
\hline 18 & Al-H-B-O-2 & & 4.53 & \\
\hline
\end{tabular}

dependent on the material type, so it is expected that $\eta$, as the same of $\gamma$, varies based on material change.

\subsection{Robustness verification of MVMEs for $R_{r}$}

To verify the reliability and robustness of the abovementioned results on MVMEs of $R_{r}$, a series of additional tests at different standoff were conducted for all three blanks. These tests and also the collected results on explosive mass are shown in Table 6. Form this table, it is obvious that the difference between explosive mass estimated through the analytical equation and taken from experiments has been dramatically decreased compared to those trials listed in Table 2.

The values of REP of estimated explosive mass, obtained from the analytical equation based on MVME of $R_{r}$ in comparison with experimental results are listed in Table 7. From this table, the mean value of REP for analytical results is around $5 \%$ with a standard deviation of 1.96. This shows using MVME of $R_{r}$ can increase the accuracy of explosive mass estimated from the analytical equation remarkably for the trials included in the scope of this study. Using this parameter, the number of trials required to obtain a successful experiment and/or FE simulation of the process is decreased.

\section{Concluding remarks}

In this research, an analytical equation to estimate the explosive mass required for cone forming was established.
The results of the analytical equation compared with the experimental trials for explosive forming of metal cones were discussed. The proposed analytical model shows that explosive mass required for the profile accomplishment is a function of material properties, standoff, cone apex angle and generally the configuration of the forming process. The effect of strain rate on the analytical computations was investigated contributing the ratio of dynamic to static flow stress. Also, the effects of redundant work and friction are indirectly represented by the coefficient of deformation efficiency. It was proposed that, to estimate the explosive mass, the ratio of dynamic to static flow stress over deformation efficiency can be used instead of both of these parameters. This new dimensionless parameter was nominated Robustness ratio $\left(R_{r}\right)$. In fact, the differences between analytical and experimental results root in two reasons: first, using the simplifications to establish the analytical model causing to decrease the strain energy estimation. Thus, to compensate for the effects of these simplifications, a higher estimation of $R_{r}$ needs to be carried out. Second, the effects of strain rate and deformation efficiency on the forming process are far more than those of the initial estimation employed in the analytical model. In the case of both points of view, $R_{r}$ may able to play a role in achieving a better estimation of explosive mass required for the complete forming process. Results of verification tests on MVME of $R_{r}$ showed that using this parameter can increase the accuracy of the analytical equation to estimate the explosive mass up to around $20 \%$. 
Table 6. Verification tests for MVMEs of $R_{r}$ : Analytical and experimental results of explosive mass.

\begin{tabular}{|c|c|c|c|c|c|c|c|c|}
\hline \multirow[t]{2}{*}{ Trial no } & \multirow[t]{2}{*}{ Material } & \multirow[t]{2}{*}{$t_{0}(\mathrm{~mm})$} & \multirow[t]{2}{*}{$D_{0}(\mathrm{~mm})$} & \multirow[t]{2}{*}{$\theta$ (degree) } & \multirow[t]{2}{*}{$S_{d}(\mathrm{~mm})$} & \multirow[t]{2}{*}{$R_{r}(\mathrm{MVME})$} & \multicolumn{2}{|c|}{ Explosive mass (gr) } \\
\hline & & & & & & & Analytical & Experimental \\
\hline 1 & $\mathrm{Cu}-\mathrm{ETP}$ & 0.8 & 100 & 60 & 170 & \multirow{6}{*}{5.29} & 7.62 & 8.00 \\
\hline 2 & $\mathrm{Cu}$-ETP & 1 & 100 & 60 & 130 & & 7.65 & 8.20 \\
\hline 3 & $\mathrm{Cu}-\mathrm{ETP}$ & 1.2 & 100 & 60 & 150 & & 11.98 & 11.65 \\
\hline 4 & $\mathrm{Cu}$-ETP & 0.8 & 110 & 45 & 150 & & 12.92 & 13.70 \\
\hline 5 & $\mathrm{Cu}-\mathrm{ETP}$ & 1 & 110 & 45 & 170 & & 21.17 & 22.00 \\
\hline 6 & $\mathrm{Cu}$-ETP & 1.2 & 110 & 45 & 130 & & 20.19 & 21.20 \\
\hline 7 & AISI 1006 & 0.8 & 100 & 60 & 130 & \multirow{6}{*}{5.49} & 6.50 & 7.00 \\
\hline 8 & AISI 1006 & 1 & 100 & 60 & 150 & & 10.87 & 10.45 \\
\hline 9 & AISI 1006 & 1.2 & 100 & 60 & 170 & & 16.82 & 17.70 \\
\hline 10 & AISI 1006 & 0.8 & 110 & 45 & 170 & & 18.05 & 18.60 \\
\hline 11 & AISI 1006 & 1 & 110 & 45 & 130 & & 18.31 & 19.60 \\
\hline 12 & AISI 1006 & 1.2 & 110 & 45 & 150 & & 28.56 & 29.15 \\
\hline 13 & $6061-\mathrm{O} \mathrm{Al}$ & 0.8 & 100 & 60 & 170 & \multirow{6}{*}{4.47} & 1.23 & 1.15 \\
\hline 14 & $6061-\mathrm{O} \mathrm{Al}$ & 1 & 100 & 60 & 150 & & 1.47 & 1.40 \\
\hline 15 & $6061-\mathrm{O} \mathrm{Al}$ & 1.2 & 100 & 60 & 130 & & 1.63 & 1.75 \\
\hline 16 & $6061-\mathrm{O} \mathrm{Al}$ & 0.8 & 110 & 45 & 170 & & 2.45 & 2.65 \\
\hline 17 & $6061-\mathrm{O} \mathrm{Al}$ & 1 & 110 & 45 & 150 & & 2.94 & 3.00 \\
\hline 18 & $6061-\mathrm{O} \mathrm{Al}$ & 1.2 & 110 & 45 & 130 & & 3.27 & 3.15 \\
\hline
\end{tabular}

Table 7. REPs of analytical estimated explosive mass in comparison with verification test results using MVME of $R_{r}$.

\begin{tabular}{|c|c|c|c|c|}
\hline \multirow[t]{2}{*}{ Trial no } & \multirow[t]{2}{*}{ Material } & \multicolumn{2}{|c|}{ Explosive weight (gr) } & \multirow{2}{*}{$\begin{array}{l}\text { REP for analytical to } \\
\text { experimental }(\%)\end{array}$} \\
\hline & & Analytical & Experimental & \\
\hline 1 & $\mathrm{Cu}-\mathrm{ETP}$ & 7.62 & 8.00 & 4.98 \\
\hline 2 & $\mathrm{Cu}-\mathrm{ETP}$ & 7.65 & 8.20 & 7.19 \\
\hline 3 & $\mathrm{Cu}-\mathrm{ETP}$ & 11.98 & 11.65 & 2.76 \\
\hline 4 & $\mathrm{Cu}$-ETP & 12.92 & 13.70 & 6.04 \\
\hline 5 & $\mathrm{Cu}-\mathrm{ETP}$ & 21.17 & 22.00 & 3.92 \\
\hline 6 & $\mathrm{Cu}-\mathrm{ETP}$ & 20.19 & 21.20 & 5.01 \\
\hline 7 & AISI 1006 & 6.50 & 7.00 & 7.70 \\
\hline 8 & AISI 1006 & 10.87 & 10.45 & 3.86 \\
\hline 9 & AISI 1006 & 16.82 & 17.70 & 5.23 \\
\hline 10 & AISI 1006 & 18.05 & 18.60 & 3.05 \\
\hline 11 & AISI 1006 & 18.31 & 19.60 & 7.04 \\
\hline 12 & AISI 1006 & 28.56 & 29.15 & 2.07 \\
\hline 13 & $6061-\mathrm{O} \mathrm{Al}$ & 1.23 & 1.15 & 6.50 \\
\hline 14 & $6061-\mathrm{O} \mathrm{Al}$ & 1.47 & 1.40 & 4.76 \\
\hline 15 & $6061-\mathrm{O} \mathrm{Al}$ & 1.63 & 1.75 & 7.36 \\
\hline 16 & $6061-\mathrm{O} \mathrm{Al}$ & 2.45 & 2.65 & 8.16 \\
\hline 17 & $6061-\mathrm{O} \mathrm{Al}$ & 2.94 & 3.00 & 2.04 \\
\hline 18 & $6061-\mathrm{O} \mathrm{Al}$ & 3.27 & 3.15 & 3.67 \\
\hline
\end{tabular}


In this research, the effect of thickness variation of blanks during the forming process was neglected. Establishing an equation in which the thickness variation is considered can be conducted as a future study.

\section{Compliance with Ethical Standards}

The authors declare that they have no conflict of interest.

I would like to show my gratitude to the Prof. Dr. IzmanSudin form Faculty of Mechanical Engineering, UniversitiTeknologi Malaysia for sharing his pearls of wisdom with me during the course of this research. I am also immensely grateful to UniversitiTeknologi Malaysia for partially financial support of this research and provide the conditions for conducting the experiments.

\section{References}

[1] R. Li, W.B. Li, X.M. Wang, W.B. Li, Effects of control parameters of three-point initiation on the formation of an explosively formed projectile with fins, Shock Waves 28, 191-204 (2018)

[2] M. Kawka, L. Olejnik, A. Rosochowski, H. Sunaga, A. Makinouchi, Simulation of wrinkling in sheet metal forming, Journal of Materials Processing Technology 109, 283-289 (2001)

[3] A.A. Dhaiban, M.E.S. Soliman, M.G. El-Sebaie, Finite element modeling and experimental results of brass elliptic cups using a new deep drawing process through conical dies, Journal of Materials Processing Technology 214, 828-838 (2014)

[4] S. Hatori, A. Sekiguchi, A. Özer, Conceptual design of multipurpose forming machine and experiments on forcecontrolled shear spinning of truncated cone, Procedia Manufacturing 15, 1255-1262 (2018)

[5] K. Bai, J. Qin, K.-M. Lee, B. Hao, Design and chatter prediction analysis of a duplex face turning machine for manufacturing disk-like workpieces, International Journal of Machine Tools and Manufacture 140, 12-19 (2019)

[6] R. Emami, A.A. Nia, Explosive forming of a steel cone using ALE method, Steel Research International 81, 737-740 (2010)

[7] R. Alipour, Impulsive sheet metal forming based on standoff charge for conical geometry, Universiti Teknologi Malaysia, 2017

[8] R. Alipour, A. Frokhi Nejad, S. Izman, M. Tamin, Computer aided design and analysis of conical forming dies subjected to blast load, Applied Mechanics and Materials 735, 50-56 (2015)

[9] S. Izman, A.F. Nejad, R. Alipour, M. Tamin, F. Najarian, Topology optimization of an asymmetric elliptical cone subjected to blast loading, Procedia Manufacturing 2, 319-324 (2015)

[10] A.C. Anastacio, C. Braithwaite, J. Kucera, E. Schmidova, J. Pachman, Shock response of polymer-bonded copper powder, Shock Waves 30, 373-384 (2020)

[11] F. Zhang, Some issues for blast from a structural reactive material solid, Shock Waves 28, 693-707 (2018)

[12] R. Alipour, F. Nadjarian, A. Alinaghizade, Inspection of geometrical integrity of work piece and measurement of tool wear by the use of photo digitizing method, International Journal of Mechanical, Aerospace, Industrial, Mechatronic and Manufacturing Engineering 4, 1426-1429 (2010)

[13] R. Alipour, F. Najarian, Using photo digitizing method to investigating of geometrical integrity of work piece and tool wear measurement, International Review of Mechanical Engineering 4, 780-784 (2010)

[14] P. Shailesh, K. Vijaya Kumar, J. Babu, K. Srinivasa Raghavan, Evaluation of strain and strain rates at different stages of superplastic cone forming, Materials Today: Proceedings 4, 835-841 (2017)

[15] M. Abedini, A.A. Mutalib, J. Mehrmashhadi, S.N. Raman, R. Alipour, T. Momeni, M.H. Mussa, Large deflection behavior effect in reinforced concrete columns exposed to extreme dynamic loads, Frontiers of Structural and Civil Engineering 14, 532-553 (2019)

[16] C. Bell, J. Corney, N. Zuelli, D. Savings, A state of the art review of hydroforming technology, International Journal of Material Forming 13, 789-828 (2019)

[17] A. Hassannejadasl, D.E. Green, S.F. Golovashchenko, J. Samei, C. Maris, Numerical modelling of electrohydraulic free-forming and die-forming of DP590 steel, Journal of Manufacturing Processes 16, 391-404 (2014)

[18] Z. Chang, M. Li, J. Chen, Analytical modeling and experimental validation of the forming force in several typical incremental sheet forming processes, International Journal of Machine Tools and Manufacture 140, 62-76 (2019)

[19] S. Peirovi, R. Alipour, A.F. Nejad, Finite element analysis of micro scale laser bending of a steel sheet metal subjected to short pulse shock wave, Procedia Manufacturing 2, 397-401 (2015)

[20] F. Najarian, R. Alipour, M.S. Rad, A.F. Nejad, A. Razavykia, Multi-objective optimization of converting process of auxetic foam using three different statistical methods, Measurement 119, 108-116 (2018)

[21] V. Ghizdavu, N. Marin, Explosive forming - economical technology for aerospace structures, INCAS, COMOTI and Henri Coanda Association 2, 107-117 (2010)

[22] R. Alipour, F. Najarian, Modeling and investigation of elongation in free explosive forming of aluminum alloy plate, World Academy of Science, Engineering and Technology 76, 490-493 (2011)

[23] R. Alipour, F. Najarian, A FEM study of explosive welding of double layer tubes, World Academy of Science, Engineering and Technology 73, 954-956 (2011)

[24] R. Alipour, Finite element analysis of elongation in free explosive forming of aluminum alloy blanks using CEL method, International Review of Mechanical Engineering 5, 1039-1042 (2011)

[25] D. Javabvar, R. Alipour, A. Alavinia, Numerical study of explosive forming of spherical shell considering explosive geometry Changes, in: 16th Annual (International) Conference of Iranian Society of Mechanical Engineering, Kerman, Iran, 63-69 (2008)

[26] R. Alipour, A.F. Nejad, H.N. Dezfouli, Steady state creep characteristics of a ferritic steel at elevated temperature: an experimental and numerical study, International Journal of Advanced Design and Manufacturing Technology 11, 115-129 (2018)

[27] R. Alipour, A.F. Nejad, Creep behaviour characterisation of a ferritic steel alloy based on the modified theta-projection data at an elevated temperature, International Journal of Materials Research 107, 406-412 (2016) 
[28] M.S. Rad, H. Hatami, R. Alipouri, A.F. Nejad, F. Omidinasab, Determination of energy absorption in different cellular auxetic structures, Mechanics \& Industry 20, 302 (2019)

[29] Ra. Alipour, R. Alipour, F. Fardian, S.S.R. Koloor, M. Petrů, Performance improvement of a new proposed Savonius hydrokinetic turbine: a numerical investigation, Energy Reports 6, 3051-3066 (2020)

[30] N. My, K. Denni, F. Najarian, R. Alipour, A.F. Nejad, Solenoid characterization on tool entrance in horizontal twist drilling process, Procedia Manufacturing 2, 1-4 (2015)

[31] D.J. Mynors, B. Zhang, Applications and capabilities of explosive forming, Journal of Materials Processing Technology 125-126, 1-25 (2002)

[32] V. Hadavi, J. Zamani, R. Hosseini, The empirical survey on the effect of using media in explosive forming of tubular shells, World Academy of Science, Engineering and Technology 60, 574-579 (2009)

[33] R. Zhang, M. Fujita, H. Iyama, Y. Ishigori, H. Osaka, K. Hokamoto, X.-Z. Zhao, Numerical analysis on deformation feature of the explosive die-forming processing, in: T. Abe, T. Tsuta (Eds.), Advances in Engineering Plasticity and its Applications (aepa 1996), Pergamon, Oxford, 1996, pp. 389-394

[34] S.A.A. Akbari Mousavi, M. Riahi, A. Hagh Parast, Experimental and numerical analyses of explosive free forming, Journal of Materials Processing Technology 187-188, 512-516 (2007)

[35] A. Farokhi Nejad, R. Alipour, M. Shokri Rad, M. Yazid Yahya, S.S. Rahimian Koloor, M. Petru, Using finite element approach for crashworthiness assessment of a polymeric auxetic structure subjected to the axial loading, Polymers 12, 1312-1326 (2020)

[36] V.N. Wijayathunga, D.C. Webb, Experimental evaluation and finite element simulation of explosive forming of a square cup from a brass plate assisted by a lead plug, Journal of Materials Processing Technology 172, 139-145 (2006)

[37] H. Mehrasa, G. Liaghat, D. Javabvar, Experimental analysis and simulation of effective factors on explosive forming of spherical vessel using prefabricated four cones vessel structures, Central European Journal of Engineering 2, 656-664 (2012)

[38] Z. Tiesheng, L. Zhensheng, G. Changji, T. Zheng, Explosive forming of spherical metal vessels without dies, Journal of Materials Processing Technology 31, 135-145 (1992)

[39] R. Zhang, H. Iyama, M. Fujita, T.-S. Zhang, Optimum structure design method for non-die explosive forming of spherical vessel technology, Journal of Materials Processing Technology 85, 217-219 (1999)

[40] R. Zhang, T.-S. Zhang, Non-die explosive forming of spherical pressure vessels, Journal of Materials Processing Technology 41, 341-347 (1994)

[41] A.F. Nejad, G. Chiandussi, V. Solimine, A. Serra, Estimation of the synchronization time of a transmission system through multi body dynamic analysis, International Journal of Mechanical Engineering and Robotics Research 6, 232-236 (2017)

[42] Ra. Alipour, R. Alipour, S.S. Rahimian Koloor, M. Petru, S. A. Ghazanfari, On the performance of small-scale horizontal axis tidal current turbines. Part 1: one single turbine, Sustainability 12, 5985 (2020)
[43] H.P. Tardif, The explosive forming of conical shapes by metal gathering, in: The Explosive Forming of Conical Shapes by Metal Gathering. 1958: Other Information: Orig. Receipt Date: 31-DEC-62, p. 8

[44] F.W. Travis, W. Johnson, The explosive forming of cones, in: The 3rd International Conference of Machine Tool Design, Birmingham, 1962, pp. 341-364

[45] A. Farokhi Nejad, G. Chiandussi, V. Solimine, A. Serra, Study of a synchronizer mechanism through multibody dynamic analysis, Proceedings of the Institution of Mechanical Engineers, Part D: Journal of Automobile Engineering 233, 1601-1613 (2019)

[46] M. Urbánek, B. Mašek, P. Hronek, P. Nesvadba, The use of explosive energy for joining advanced high strength low alloy steels, Journal of Materials Engineering and Performance 22, 748-752 (2013)

[47] S. Sen, I.G. Aksoy, An application of explosive metal forming in military field: the relationship between shaped charge jet formation and thickness variation along liner length of conical copper liner, Arabian Journal for Science and Engineering 38, 3551-3562 (2013)

[48] M. Abedini, A.A. Mutalib, S.N. Raman, R. Alipour, E. Akhlaghi, Pressure-Impulse (P-I) diagrams for Reinforced Concrete (RC) structures: a review, Archives of Computational Methods in Engineering 26, 733-767 (2018)

[49] F. Najarian, R. Alipour, A. Razavykia, A.F. Nejad, Hole quality assessment in drilling process of basalt/epoxy composite laminate subjected to the magnetic field, Mechanics \& Industry 20, 620 (2019)

[50] O.E. Kosing, B.W. Skews, An investigation of high-speed forming of circular plates in a liquid shock tube, International Journal of Impact Engineering 21, 801-816 (1998)

[51] H. Fengman, T. Zheng, W. Ning, H. Zhiyong, Explosive forming of thin-wall semi-spherical parts, Materials Letters 45, 133-137 (2000)

[52] R. Alipour, S. Izman, M.N. Tamin, Estimation of charge mass for high speed forming of circular plates using energy method, in: Advanced Materials Research, Trans Tech Publications Ltd. 845, 803-808 (2014)

[53] O. Gulcan, N. Gemalmayan, B. Tuc, Optimization of explosive mass in explosive forming process by using genetic algorithm, Canadian Journal on Mechanical Sciences and Engineering 1, 1-9 (2010)

[54] N. Nariman-Zadeh, A. Darvizeh, A. Jamali, A. Moeini, Evolutionary design of generalized polynomial neural networks for modelling and prediction of explosive forming process, Journal of Materials Processing Technology 164-165, 1561-1571 (2005)

[55] S. Balasubramaniam, S.S. Ali, E.S.B. Rao, Explosive forming of low carbon steel sheet into a stepped disc shape, Defence Science Journal 34, 235-256 (1984)

[56] S. Itoh, Chapter 32-Shock waves in liquids, in: G. Ben-Dor, O. Igra, T.O.V. Elperin (Eds.)Handbook of Shock Waves, Academic Press Burlington, 2001 pp. 263-314

[57] M. Fujita, Y. Ishigori, S. Nagano, N. Kimura, S. Itoh, Explosive precision of fine arts using regulated underwater shock wave, in: W.B. Lee, (Editor), Advances in Engineering Plasticity and its Applications, Elsevier, Oxford, 1993, pp. 1007-1012

[58] R. Cole, Underwater explosions. Princeton univ. Press, Princeton, New Jersey, 1948 
[59] S. Rao, R. Vijayakumar, Underwater explosion and effect on structures, International Journal of Innovative Research and Development 1, 207-234 (2012)

[60] C.D. Sulfredge, R.H. Morris, R.L. Sanders, Calculating the effect of surface or underwater explosions on submerged equipment and structures, in: James Chapman, Proceedings of the American Nuclear Society International Topical Meeting on Probabilistic Safety Analysis (PSA'05), 2005

[61] A.A. Ezra, Principles and practice of explosive metalworking, Industrial Newspapers, London, UK, 1973

[62] W.F. Hosford, R.M. Caddell, Metal forming: mechanics and metallurgy, Cambridge University Press, Cambridge, UK, 2011

[63] W.F. Hosford, Fundamentals of engineering plasticity, University Press, Cambridge, UK, 2013

[64] S. Semiatin, A.I.H. Committee, Forming and forging, American Society for Metals, Geauga County, OH, USA, 1996

[65] A. Bebb, Under-water explosion measurements from small charges at short ranges, Philosophical Transactions of the Royal Society of London A: Mathematical, Physical and Engineering Sciences 244, 153-175 (1951)

[66] J. Chakrabarty, Theory of plasticity, Butterworth-Heinemann, Oxford, UK, 2012

[67] A.S. Khan, S. Huang, Continuum theory of plasticity, John Wiley \& Sons, Hoboken, NJ, USA, 1995

[68] W.F. Hosford, Mechanical behavior of materials, Cambridge University Press, Cambridge, UK, 2010

[69] K. Kawata, J. Shioiri, Constitutive Relation in High/Very High Strain Rates: IUTAM Symposium Noda, Japan October 16-19, 1995, Springer Science \& Business Media, Medford, MA 02155, USA, 2013

[70] S. Mohsenizadeh, Z. Ahmad, R. Alipour, R.A. Majid, Y. Prawoto, Quasi tri-axial method for the fabrication of optimized polyurethane auxetic foams, Physica Status Solidi (b) 256, 1800587 (2019)
[71] M.D. Theobald, G.N. Nurick, Experimental and numerical analysis of tube-core claddings under blast loads, International Journal of Impact Engineering 37, 333-348 (2010)

[72] Chakrabarty, Applied plasticity, 2nd Ed, 88, Springer, New York City, NY, USA, 2010

[73] G. Gray, H. Kuhn, D. Medlin, ASM Handbook, vol. 8, Mechanical Testing and Evaluation, ASM International, Materials Park, Novelty, OH 44072, USA, pp. 462, 2005

[74] W. Johnson, Impact strength of materials, Edward Arnold, London, UK, 1972

[75] M.A. Meyers, Dynamic behavior of materials, Wiley, Hoboken, NJ, USA, 1994

[76] V. Boljanovic, Sheet metal forming processes and die design, Industrial press, Norwalk, CT 06854, USA, 2014

[77] V. Miguel, A. Martínez, J. Coello, F.J. Avellaneda, A. Calatayud, A new approach for evaluating sheet metal forming based on sheet drawing test. Application to TRIP 700 steel, Journal of Materials Processing Technology 213, 1703-1710 (2013)

[78] H. Goldstein, Classical mechanics, 2nd ed. Addison-Wesley, Boston, MA, USA, 1980

[79] R.L. Holloman, V. Deshpande, H.N. Wadley, Impulse transfer during sand impact with a solid block, International Journal of Impact Engineering 76, 98-117 (2015)

[80] R. Rajendran, J.M. Lee, Blast loaded plates, Marine Structures 22, 99-127 (2009)

[81] B. Song, D. Casem, J. Kimberley, Dynamic Behavior of Materials, Volume 1: Proceedings of the 2013 Annual Conference on Experimental and Applied Mechanics, Springer Science \& Business Media, Medford, MA 02155, USA, 2013

[82] H. Tschaetsch, Metal forming practise, Springer Berlin Heidelberg, Germany, 2006

Cite this article as: R. Alipour, Physically-based modelling for sheet metal cone parts forming under blast loading, Mechanics \& Industry 22, 3 (2021) 